\title{
Dermoscopy as an auxiliary tool for the diagnosis of furuncular myiasis*
}

Fred Bernardes Filho ${ }^{1}$

Eduarda Faísca Barbará ${ }^{3}$

Ricardo Luis Passos Coelho Filho ${ }^{4}$

\author{
Gustavo Martins ${ }^{2}$ \\ Maria Luiza Barros de Paiva ${ }^{4}$ \\ José Augusto da Costa Nery ${ }^{5}$
}

DOI: http://dx.doi.org/10.1590/abd1806-4841.20142975

Abstract: Furuncular myiasis occurs after larvae penetrate on the skin. The disease is characterized by the presence of a nodule with a central hole through which there is serosanguinous exudate drainage. The authors present a case of furuncular myiasis by Dermatobia hominis in which late diagnosis made it necessary to have the orifice margins surgically enlarged in order to extract the larva. They also emphasize that dermoscopy is a useful auxiliary tool in this diagnosis.

Keywords: Dermoscopy; Diptera; Myiasis

A fifty-eight year-old male gardener related a persistent, non-healing wound on the left leg, for the previous 15 days. He had no recollection of local trauma and affirmed he had used ointments and creams, prescribed in two previous consultations, without improvement on the lesion. The patient denied other comorbidities and allergies. Dermatological examination found an erythematous nodule with a central orifice on the left leg (Figure 1). Initial clinical hypotheses were: furuncular myiasis, sporotrichosis and a lesion caused by foreign body. After the occlusion of the nodule, dermoscopy helped to establish the correct diagnosis by allowing the visualization of vertical movement (surfacing and submerging) of a structure with two yellow points on top, corresponding to the spiracles on the posterior end of the larva (Figures 2 and 3). After several unsuccessful attempts to extract the maggot, we proceeded with local anesthesia and expansion of the lesion's orifice, whereas the insect was removed (Figure 4).

Myiasis is a dermatozoonosis caused by larvae of the order Diptera in organs and tissues of man or other vertebrate animals, where they feed and develop as parasites. ${ }^{1}$ It is universally distributed and it can affect patients of any sex, age or race. Myiasis can be

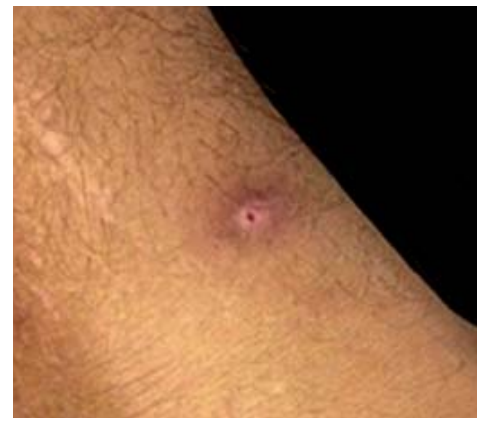

FIGURE 1:

Erythematous nodule with central hole on the inferior middle third of the left leg

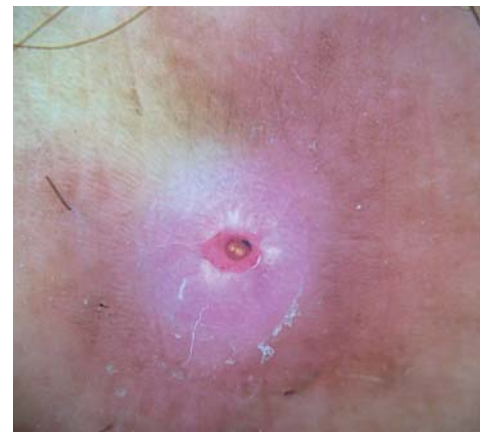

Figure 2:

Dermoscopy showing the larva surfacing at the center of the lesion, after the occlusive alcohol-gel patch was removed

* Work performed at Prof. Rubem David Azulay Dermatology Institute at Rio de Janeiro Santa Casa da Misericórdia Hospital (IDPRDA-SCMRJ) - Rio de Janeiro (RJ) - Brazil.

Conflict of interest: None

Financial funding: None

Prof. Rubem David Azulay Dermatology Institute at Rio de Janeiro Santa Casa da Misericórdia Hospital (IDPRDA-SCMRJ) - Rio de Janeiro (RJ) - Brazil.

Private Practice - Ituiutaba (MG), Brazil.

Universidade Estácio de Sá - Rio de Janeiro (RJ) - Brazil.

Petrópolis Medical School- Petrópolis (RJ) - Brazil.

Instituto Oswaldo Cruz - Fundação Oswaldo Cruz (FIOCRUZ) - Rio de Janeiro (RJ), Brazil. 


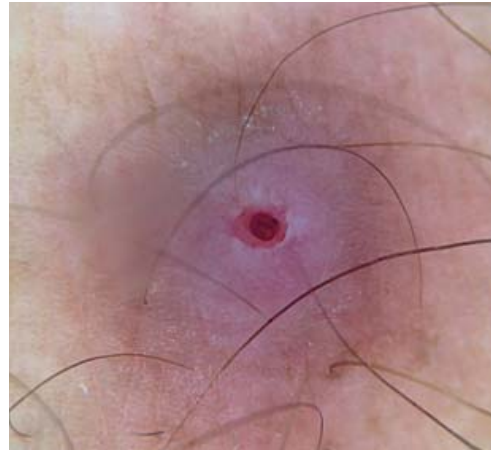

FIGURE 3:

Dermoscopy showing details of the cavity after the larva submerged in it

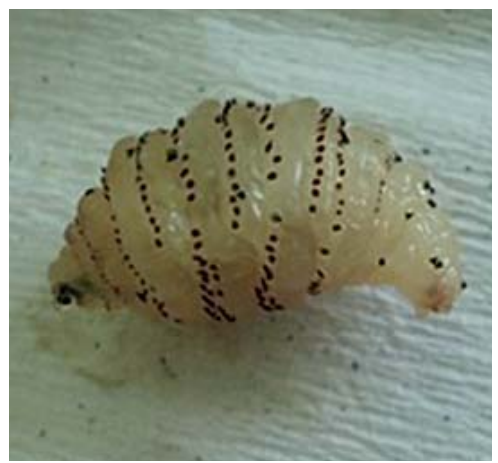

FIGURE 4:

Dermatobia hominis - larva extracted from the lesion

classified according to area of occurrence as cutaneous, subcutaneous or cavitary., ${ }^{2,3}$ The biological characteristics of the fly, can be categorized into: obligatory (primary or biontophagous), in which larvae develop by feeding on living tissue; facultative (secondary or necrobiontophagous), caused by larvae of flies that develop in decaying organic matter or accidental, caused by larvae ingested with food. . $^{1,3,4}$

Furuncular cutaneous myiasis is the most common clinical presentation of the disease, with the typical lesion being distinguished by a painful and inflammatory papule or nodule of furuncular aspect, with a central hole that drains out a slight serosan- guinous exudate. ${ }^{5}$ Pruritus, sensation of larval movement and pain may also be reported. Secondary infection is the main complication. In Brazil, the most common agent is Dermatobia hominis. ${ }^{2}$

When the insect approaches a mammal to feed or rest, larvae are stimulated by heat, carbon dioxide and odors emitted from the host, thus leaving the eggs and actively penetrating the skin. ${ }^{5}$ The respiratory portion (spiracle) faces the outer part of the skin as the anterior part of the larva stays submerged in the dermis, where it feeds on purulent and necrotic materials in the lesion. ${ }^{1}$ Parasitism lasts for approximately 30 days in humans. ${ }^{2,3}$

Entodermoscopy involves the application of dermoscopy to help diagnose and monitor the treatment of infestations such as scabies, pediculosis, tungiasis, larva migrans, tick infestations and reactions to spider leg spines. ${ }^{6}$ Dermoscopic patterns that assist in the diagnosis of myiasis have already been described. ${ }^{7.89}$

Dermoscopy descriptions of furuncular myiasis reported in the literature mentioned a central opening, surrounded by dilated blood vessels, containing a yellowish structure with black spines. Also reported were structures described as bird's feet-like, corresponding to respiratory spiracles and black dots on the outer edge of the larva similar to a thorn crown. ${ }^{7,89}$

Recognition of man as a possible host of larvae is important in medicine, as it may cause irritation, discomfort, itching, insomnia and general physical disabilities, especially in large infestations. The proximal extremity of the larva can be easily visible to the naked eye, but in cases in which the aperture is too small, it may be difficult to visualize, making the use of dermatoscopy useful to confirm the diagnosis of myiasis. Early recognition and appropriate treatment of the disease permit clinical cure to be achieved and prevent the need for surgical intervention to extract the maggot, a fact that could not be avoided in the case reported due to the time of evolution and size of the larva.] 


\section{REFERENCES}

1. Burns DA. Diseases Caused by Arthropods and Other Noxious Animals. In: Burns T, Breathnach S, Cox N, Griffiths C, editors. Rook's Textbook of Dermatology. 8th ed. Oxford: Wiley Blackwell; 2010 p. 38.2, 38.8-11.

2. Azulay RD, Azulay DR. Dermatozoonozes. Dermatoses por dípteros. Mí́ase. In: Azulay RD, Azulay DR, Azulay-Abulafia L. Dermatologia 5. ed. Rio de Janeiro: Guanabara Koogan; 2008. p. 482-4.

3. Caumes E, Carrière J, Guermonprez G, Bricaire F, Danis M, Gentilini M. Dermatoses associated with travel to tropical countries: a prospective study of the diagnosis and management of 269 patients presenting to a tropical disease unit. Clin Infect Dis. 1995; $20: 542-8$.

4. Maier $\mathrm{H}$, Honigsmann $\mathrm{H}$. Furuncular myiasis caused by Dermatobia hominis, the human botfly. J Am Acad Dermatol. 2004:50:S26-30.

5. Neves DP. Parasitologia humana. 10. ed. São Paulo: Atheneu; 2000.

6. Zalaudek I, Giacomel J, Cabo H, Di Stefani A, Ferrara G, Hofmann-Wellenhof R, et al. Entodermoscopy: a new tool for diagnosing skin infections and infestations. Dermatology. 2008;216:14-23.

7. Abraham LS, Azulay-Abulafia L, Aguiar Dde P, Torres F, Argenziano G. Dermoscopy features for the diagnosis of furuncular myiasis. An Bras Dermatol. 2011;86:160-2.

8. Bastos CAS. Non-traditional Indications in dermoscopy. Surg Cosmet Dermatol. 2012;4:203-5.

9. Bakos RM, Bakos L. Dermoscopic diagnosis of furuncular myiasis. Arch Dermatol. 2007;143:123-4
MAILING ADDRESS:

Fred Bernardes Filho

Rua Marquês de Caxias, 9 - Sobrado - Centro 24030-050 - Niterói - RJ

Brazil

E-mail:f9filho@gmail.com

How to cite this article: Bernardes Filho F, Martins G, Barbará EF, Paiva MLB, Coelho RLP, Nery JAC. Dermoscopy as an auxiliary tool for the diagnosis of furuncular myiasis. An Bras Dermatol. 2014;89(4):663-5. 